\title{
Monitoring the Topography of a Dynamic Tidal Inlet Using UAV Imagery
}

\author{
Nathalie Long ${ }^{1, *}$, Bastien Millescamps ${ }^{1}$, Benoît Guillot ${ }^{2}$, Frédéric Pouget ${ }^{1}$ and Xavier Bertin ${ }^{1}$ \\ 1 Littoral, Environnement et Sociétés, Université de la Rochelle-CNRS, 2 rue Olympe de Gouges, \\ La Rochelle 17000, France; bastien.millescamps@univ-lr.fr (B.M.); frederic.pouget@univ-lr.fr (F.P.); \\ xavier.bertin@univ-lr.fr (X.B.) \\ 2 Environnements et Paléoenvironnements Océaniques et Continentaux, Université de Bordeaux-CNRS, \\ Allée Geoffroy Saint-Hilaire, Pessac 33615, France; benoit.guillot@u-bordeaux.fr \\ * Correspondence: nathalie.long@univ-lr.fr; Tel.: +33-05-4650-7633
}

Academic Editors: Deepak R. Mishra, Richard W. Gould Jr. and Prasad S. Thenkabail Received: 31 December 2015; Accepted: 27 April 2016; Published: 6 May 2016

\begin{abstract}
Unmanned Aerial Vehicles (UAVs) are being increasingly used to monitor topographic changes in coastal areas. Compared to Light Detection And Ranging (LiDAR) data or Terrestrial Laser Scanning data, this solution is low-cost and easy to use, while allowing the production of a Digital Surface Model (DSM) with a similar accuracy. Three campaigns were carried out within a three-month period at a lagoon-inlet system (Bonne-Anse Bay, La Palmyre, France), with a flying wing (eBee) combined with a digital camera. Ground Control Points (GCPs), surveyed by the Global Navigation Satellite System (GNSS) and post-processed by differential correction, allowed georeferencing DSMs. Using a photogrammetry process (Structure From Motion algorithm), DSMs and orthomosaics were produced. The DSM accuracy was assessed against the ellipsoidal height of a GNSS profile and Independent Control Points (ICPs) and the root mean square discrepancies were about 10 and $17 \mathrm{~cm}$, respectively. Compared to traditional topographic surveys, this solution allows the accurate representation of bedforms with a wavelength of the order of $1 \mathrm{~m}$ and a height of $0.1 \mathrm{~m}$. Finally, changes identified between both main campaigns revealed erosion/accretion areas and the progradation of a sandspit. These results open new perspectives to validate detailed morphological predictions or to parameterize bottom friction in coastal numerical models.
\end{abstract}

Keywords: UAV photogrammetry; coastal monitoring; tidal inlet; sandspit

\section{Introduction}

Due to their exposure to both marine and terrestrial natural processes as well as anthropogenic activities, coastal environments can exhibit fast morphological changes. To improve the knowledge about these processes, a first step is often to perform repetitive topographic surveys. In particular, the morphology of small estuaries and inlets evolves very quickly and can change drastically within several weeks only. Therefore, accurate data with a high temporal frequency are often required [1-4] and several solutions have emerged over the last decade. Satellite images were used to delineate coastal landforms and to demonstrate their temporal changes [5-8]. Digital Surface Models (DSM) can also be generated from tri-stereo images, as was recently achieved with Pleiades images $[9,10]$. Light Detection and Ranging (LiDAR) and Terrestrial Laser Scanning (TLS) allow the generation of accurate DSMs in coastal areas with a comparable spatial resolution [11-13]. However, the availability of satellite images is not guaranteed under bad weather conditions while the high cost of LiDAR and TLS acquisition can limit the number of campaigns.

Atlantic European coasts are exposed to winter storms that can induce coastal damage $[14,15]$. In France, the retreat of the coastline can reach several tens of meters per year [16] and impact 
infrastructure located on the beachfront, with significant socio-economic consequences. To monitor these rapid and substantial morphological changes, an Unmanned Aerial Vehicle (UAV) combined with a digital camera appears as an attractive solution. Indeed, several studies have demonstrated the performance of this technique in coastal areas, with a vertical accuracy of the DSM of the order of $\pm 10 \mathrm{~cm}$ [17-19]. While UAVs are limited by meteorological conditions (wind speed has to be typically lower than $70-80 \mathrm{~km} / \mathrm{h}$ along with no rain) and the size of the study area (typically of the order of $1 \mathrm{~km}^{2}$ ), they are able to collect images that allow the generation of a three-dimensional (3D) point cloud and DSM by a process of photogrammetry. The accuracy of the resulting DSM was already shown to be similar to that of LiDAR data [20]. Several types of UAVs with different on-board sensors are available, adapted for each type of environment [21,22]. Compared to other methods discussed above, UAVs combine several advantages that were summarized by Gonçalves and Henriques [17]: (1) a high level of automation of photographic survey; (2) a very low operating cost; (3) a high repeatability of the survey; (4) the possibility to obtain aerial photography with centimetric resolution. In addition, UAV mapping methods are evolving quickly and are subjected intense developments. Thus, Jutzi et al. [23] combined a camera and an active sensor (lightweight laser-scanner line) to produce DSMs in complex environments without ground control points. Other innovations concern visualizing data from UAVs in 3D on a virtual globe, both in real time and after landing [24].

This study aims at assessing the applicability of photogrammetry from UAV to a lagoon-inlet system, to generate high resolution DSMs and provide a detailed description of the morphological changes that the inlet experienced over a three-month summer period.

\section{Study Area}

The study area corresponds to the Bonne-Anse Lagoon-Inlet system, located at the mouth of the Gironde Estuary, in the central part of the Bay of Biscay (Atlantic coast, La Palmyre, France). This lagoon-inlet was selected because of the fast evolution of this system, mostly intertidal under spring tides. The mouth of the bay is $2 \mathrm{~km}$ long and $1.5 \mathrm{~km}$ wide. This tidal inlet is composed of well-developed flood and ebb deltas and a main channel, which allows navigation to the small recreational harbor of La Palmyre City (Figure 1). The shape of the inlet itself evolves very quickly, moving from a convex to a concave shape. Over the past 15 years, the main channel migrated to the southeast at a mean rate of $93 \mathrm{~m} \cdot$ year $^{-1}$ with a maximum value of $193 \mathrm{~m} \cdot$ year $^{-1}[7,8]$.

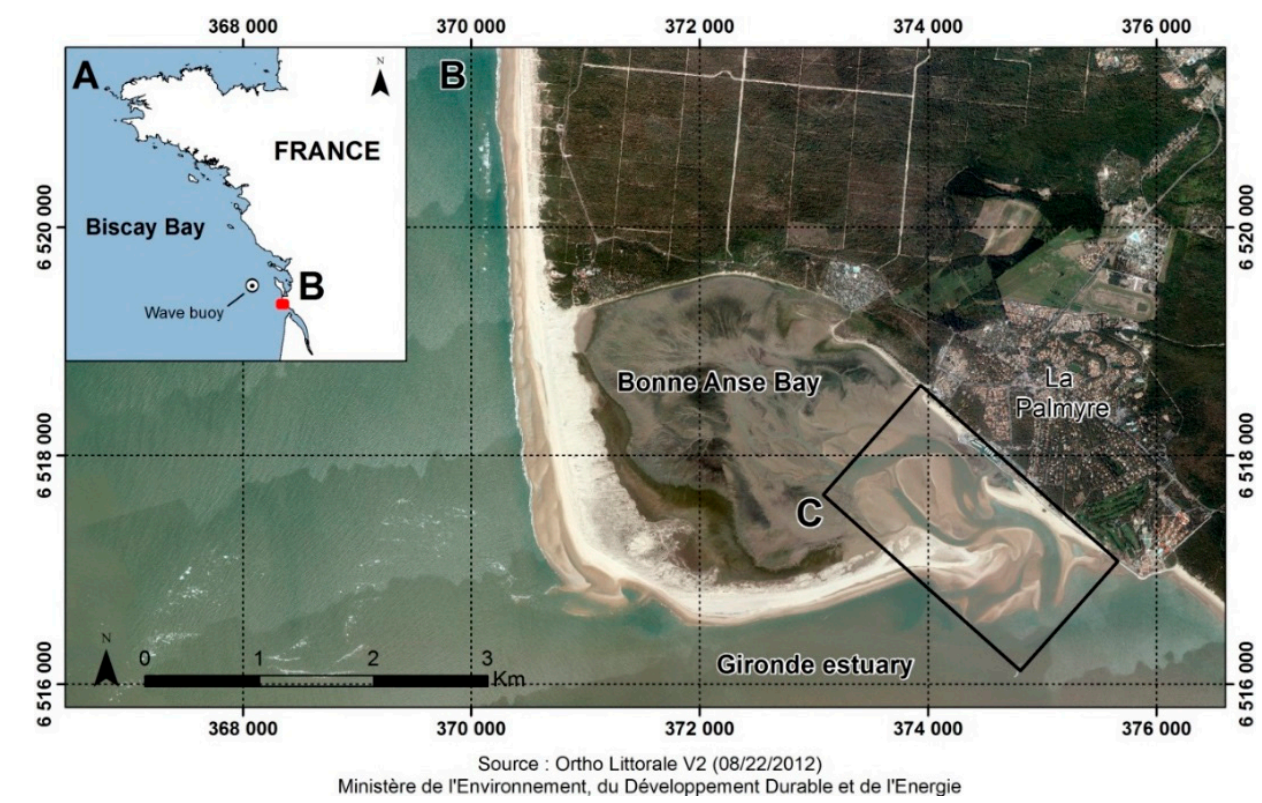

Figure 1. Location of the study area (A) on the Atlantic coast of France; (B) the Bonne-Anse Lagoon-Inlet; and (C) the study area (Lambert 93 Projection). 


\section{Materials and Methods}

\subsection{UAV Characteristics}

The UAV data used in this study were obtained using the eBee flying wing, developed by the SenseFly Company (Cheseaux-sur-Lausanne, Switzerland). This flying wing is a very light UAV (700 $\mathrm{g}$ with the camera) and its wingspan is $96 \mathrm{~cm}$ (Figure 2). eBee is an autonomous UAV with an on-board artificial intelligence system, which analyzes data from an Inertial Measurement Unit (IMU) and an on-board GPS to optimize every aspect of its flight. The main advantage of this flying wing compared to a multicopter is the size of the overflow area per flight but the wind speed has to be lower than $40 \mathrm{~km} / \mathrm{h}$. A lithium polymer battery provides at least $50 \mathrm{~min}$ of continuous operation. A radio linked $(2.4 \mathrm{GHz})$ by a modem allows communications between the software/pilot and the UAV up to a distance of $3 \mathrm{~km}$. The flight is operated with the eMotion ${ }^{\circledR}$ software, provided with the eBee. This software allows planning the flight before the mission and to interact with the UAV during the flight. All the parameters, such as the height of the flight, the overlap between the images or the images' spatial resolution, are user-specified before each flight. A flight simulation, where a fixed wind speed and direction are considered, allows verifying the overflow area and the autonomy of the UAV (or if several flights are needed). The number of photos, the flying time and the surface of the covered area are also computed through this simulation. After the flight, the same software is used to georeference all the images according to the flight effectively performed recorded by the onboard GNSS.

The UAV is equipped with a CANON Powershot ELPH110 HS RGB camera with a resolution of 16.1 Mpixel. Its focal length ranges from $4.3 \mathrm{~mm}$ and $21.5 \mathrm{~mm}$, which for a flight height of $150 \mathrm{~m}$, for example, yields a ground sampling distance of $4.69 \mathrm{~cm}$.

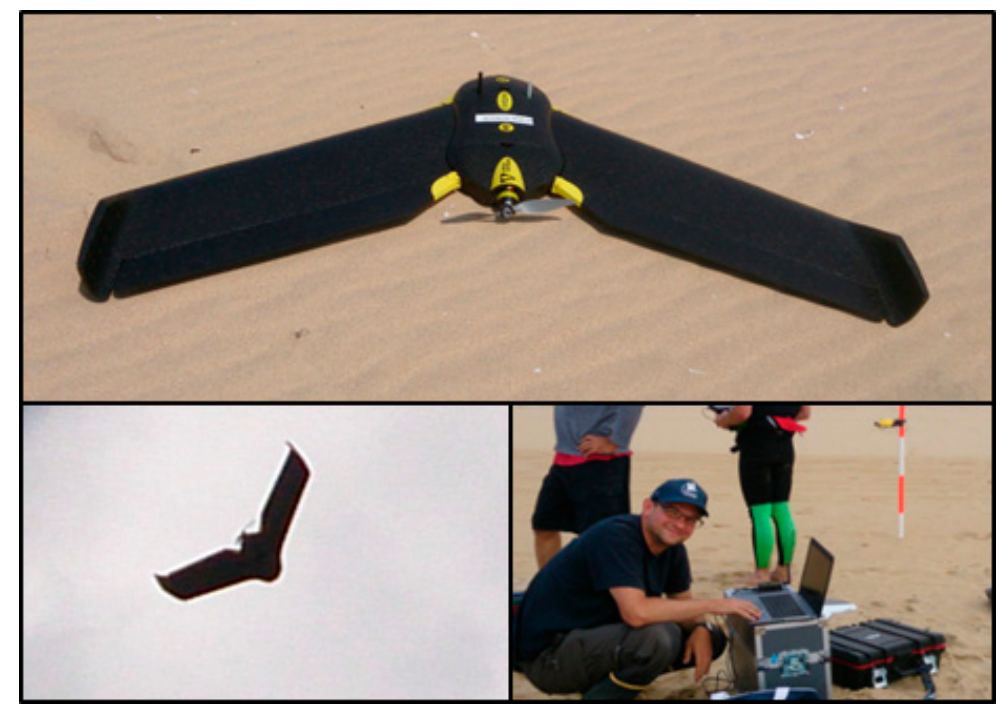

Figure 2. eBee UAV during a field campaign, in flight and the hardware.

\subsection{Photogrammetry Process}

To monitor coastal topography, a 3D analysis is required. For a 3D reconstruction, a photogrammetry process is used, based on the Structure From Motion (SFM) algorithm. The photogrammetry is a technique which allows reconstructing a relief from several stereoscopic images of the same object. Basically, the SFM algorithm allows reconstructing a 3D scene geometry from a set of images of a static scene by matching features on multiple images. A 3D point cloud is generated and georeferenced using ground control points (hereafter GCP). The SFM algorithm is based on a multi-view of the scene and the redundancy of the information allows the success of this 
process [25-27]. Mancini et al. [19] have compared the accuracy of the DSMs generated from TLS data and UAV data using the SFM algorithm and showed that the elevation accuracies were similar.

The SFM algorithm is available in several softwares to generate DSMs and orthomosaics. Free or open-source software such as Cloud Compare, Mic-Mac [28] or Opensource Photogrammetry can also be used. We have chosen the Agisoft Photoscan ${ }^{\circledR}$ Professional Edition software (version 1.1.6), which is well suited to UAV image processing [29]. The workflow proposed by Photoscan to generate a DSM is divided into different steps and uses a well-known photogrammetric approach (Figure 3). The first stage is the image alignment. At this stage, common points on images are identified and matched, as well as the position of the camera for each image. The camera calibration parameters are refined. The values for the initial camera parameters are taken from the EXIF (EXchangable Image file Format) header:

- $\mathrm{fx}$, fy: focal length in $\mathrm{x}$ - and $\mathrm{y}$-dimensions measured in pixels,

- $\quad c x, c y:$ principal point coordinates, i.e., coordinates of lens optical axis interception with sensor plane,

- skew: skew transformation coefficient,

- $\mathrm{k} 1, \mathrm{k} 2, \mathrm{k} 3$ : radial distortion coefficients,

- $\quad$ p1, p2: tangential distortion coefficients.

GCPs are introduced in the model to perform the image alignment. Each GCP is manually assigned to one image where the target is visible and recognizable, and then automatically assigned to every other image that contains the same GCP. This step is concluded by a last optimization image alignment. The possible non-linear deformations of the model can be removed by optimizing the estimated point cloud and camera parameters based on the known reference coordinates. During this optimization, estimated point coordinates and camera parameters are adjusted to minimize the sum of reprojection errors and reference coordinate misalignment errors.

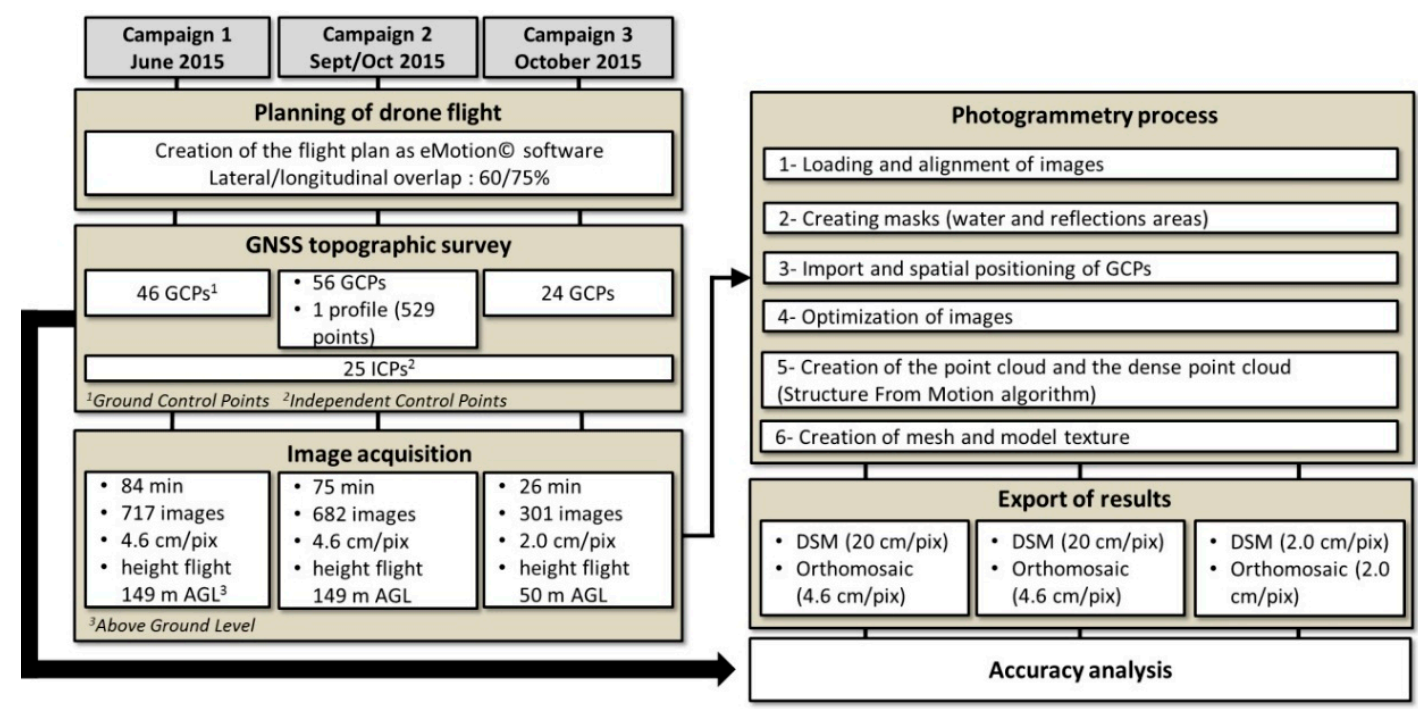

Figure 3. General overview of methods, starting with the preparation of overflight drone campaigns until the determination of DSM and orthomosaic accuracy by GNSS data (profile and ICPs).

Then, a dense point cloud is computed, georeferenced in a real-world coordinate system, and a triangular mesh is built. Lastly, the mosaic of images is draped on the mesh to produce an orthomosaic. The results (DSM and orthomosaic) are exported according to a selected projection system and a spatial resolution. 


\subsection{Field Campaigns and Data Acquisition}

\subsubsection{Image Acquisition}

To study the spatial variability of the topography of the Bonne Anse Lagoon-Inlet, three campaigns were executed in June, September and October 2015. The same flight plan was used: three flights were necessary to cover the whole area. Campaigns 1 (16 June 2015) and 2 (28 September 2015 and 2 October 2015) cover the whole study area (three flights per campaign). On the 2 October 2015, an additional flight was realized at a lower altitude $(50 \mathrm{~m}$ ) over the flood delta (campaign 3), in order to provide a higher spatial resolution (Figure 3). The height of the flights was about $149 \mathrm{~m}$ above the ground level (AGL) on average for the two first campaigns, which yields images with a $4.6 \mathrm{~cm}$ spatial resolution. For the third campaign, the $50 \mathrm{~m}$ AGL yielded a spatial resolution of $2 \mathrm{~cm}$. The latitudinal overlap was $60 \%$ and the longitudinal overlap was $75 \%$. The flight plans were prepared on the eMotion ${ }^{\circledR}$ software and the mission area was saved in order to repeat the same mission from one campaign to another. Only the direction of the flight was adapted to the wind direction, considering that the UAV has to fly against the wind to provide better-quality images. Around 700 photos were recorded to cover this area of about 400 ha (Figure 3).

The meteorological conditions and the tidal level varied between the three campaigns: for campaign 1, the wind was very irregular with strong gusts; the UAV lost its trajectory several times and had to come back on the right trajectory. For campaigns 2 and 3, the wind speed was moderate but regular, and in October, the wind speed was very low so the flights occurred without any problem. The tidal range was slightly different: $3.95 \mathrm{~m}$ for campaign 1 against $4.75 / 4.10 \mathrm{~m}$ for campaigns 2 and 3 (Table 1).

Table 1. Meteorological conditions, tidal ranges and tidal levels with respect to marine charts datum for the three campaigns.

\begin{tabular}{ccccc}
\hline Date & Wind Speed $(\mathbf{m} / \mathbf{s})$ & Wind Direction $\left({ }^{\circ}\right)$ & Tidal Range $(\mathbf{m})$ & Tidal Level $(\mathbf{m})$ \\
\hline 16 June 2015 & $5-7$ & 20 & 3.95 & 1.15 \\
28 September 2015 & $9-11$ & 70 & 4.75 & 0.80 \\
2 October 2015 & 2 & 70 & 4.10 & 1.15 \\
\hline
\end{tabular}

\subsubsection{GNSS Surveys}

GCPs are required for the georeferencing. In natural environments in general and in coastal areas in particular, a few time-invariant objects can usually be identified. Therefore, artificial targets were also used: white sheets of paper were deployed on the ground and were partially buried because of the wind. These artificial targets were placed and their coordinates were surveyed, just before low tide, to realize the flight before the rising tide. Forty-six and 56 targets were placed and surveyed using GNSS receivers for the two first campaigns, respectively. For the third campaign, 24 GCPs were acquired (Figure 3). GCPs were roughly equally dispatched with two GNSS receivers (Figure 4). For campaign 2, a 677 m GNSS profile with 529 points was also surveyed, crossing the flood delta in front of the harbor entrance (Figure $4 \mathrm{~b}$ ). Then, to evaluate vertical and horizontal errors, complementary GNSS measurements were carried out in February 2016 on stable areas of the study site (sea promenade, bike path and parking lot). A total of 25 independent check points (ICPs) were surveyed (Figure 4a,b). 


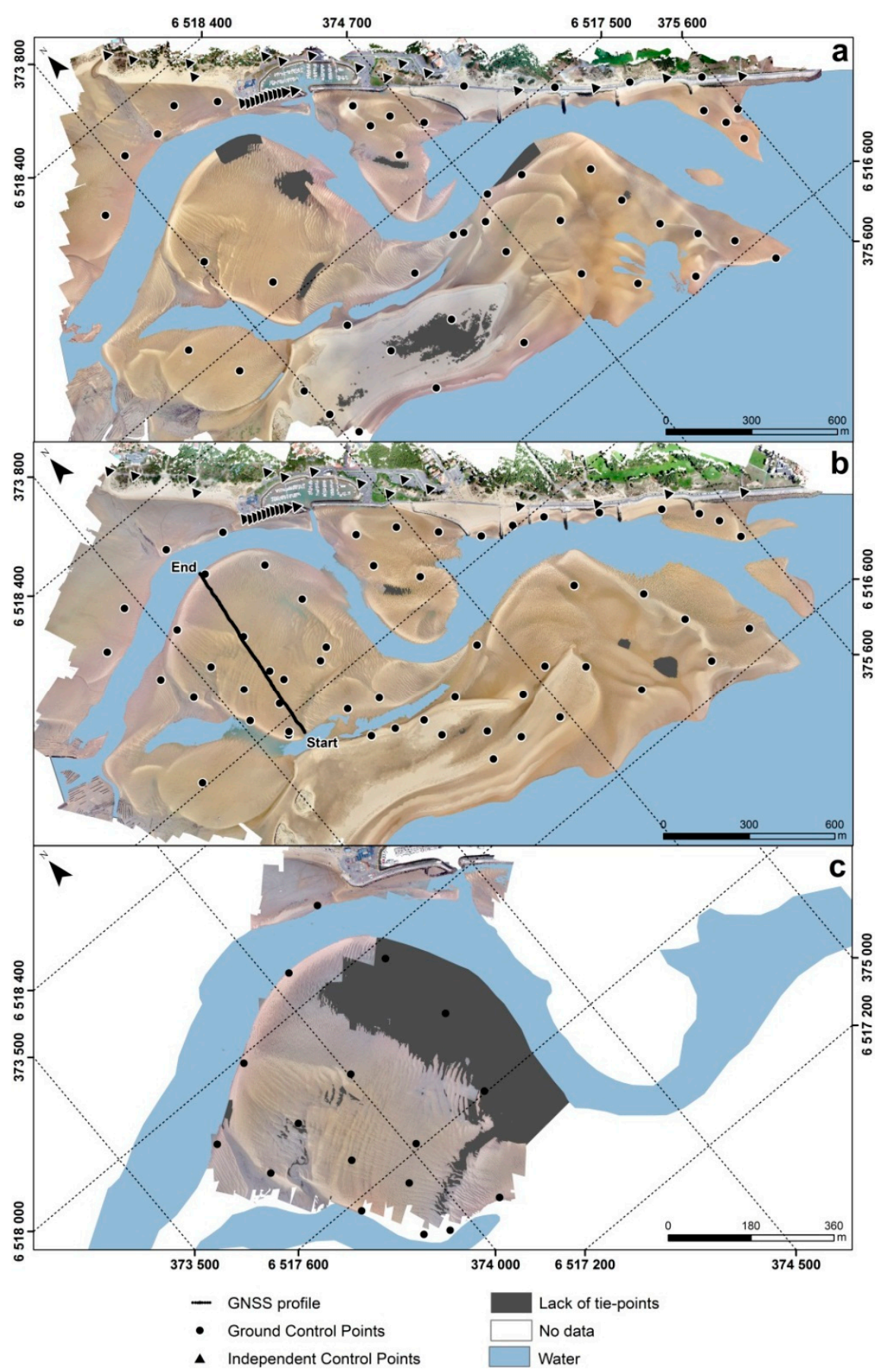

Figure 4. Orthomosaics of the three campaigns: (a) campaign 1; (b) campaign 2 and (c) campaign 3. Location of the GCPs (black circles), the ICPs (black triangles) and the profile used to estimate the accuracy of the DSMs. The grey areas correspond to areas where the photogrammetric processes failed due to the lack of tie points. White areas correspond to areas where no data were available. Blue areas correspond to subtidal/water areas.

The following methodology was applied to perform and post-process the GNSS surveys: a base station was settled immediately near the zone of study, less than $3 \mathrm{~km}$ of the farthest region of the flying zone. Beforehand, this station was the object of a long-term measurement with differential correction (with a permanent GPS network), which allowed determining its coordinates (X, Y and ellipsoidal height) with a precision better than $10 \mathrm{~cm}$. A fixed GNSS receiver was placed on this base station during all GNSS measurements. At the end of the session, a differential correction with regard to the 
fixed station was performed for all the observations obtained on the ground. The first GNSS receiver used was a GeoXH (Trimble) decametric GNSS and it was used only for campaign 1. The data was post-processed following a Post-Processing Kinematic (PPK) method, with the base station of "Royan" (at a distance of $13 \mathrm{~km}$ to the southeast of the study area), using the GPS Pathfinder (Trimble) software. This base station is a permanent GNSS station, part of the French Geographical Institute GNSS Network (IGN-RGP). Considering the extension of the surveyed area, a second GNSS receiver, a Topcon Hiper Pro, was used to complete the topographic acquisitions. The data acquired with this receiver was post-processed with the same PPK method. The software used for this post-processing was RTKLib, an open-source software [30]. The measuring time was $2 \mathrm{~min}$ for each point, with a time step of $1 \mathrm{~s}$. The respective heights of the GNSS antenna and the base were measured for each campaign and used for the post-processing. All field data were acquired in WGS84. Applying this methodology, an interruption of the radio connection between the base and the receiver does not disturb the survey and allows a guaranteed vertical absolute precision better than $8 \mathrm{~cm}$ and an horizontal absolute precision around $1 \mathrm{~cm}$, according to comparisons previously performed by our group at several geodetic points.

\subsection{Vertical and Horizontal Discrepancy}

To assess the vertical accuracy of UAV-derived DSMs, the arithmetic average discrepancy and the root mean square discrepancy (RMSD) were calculated based on the difference between the ellipsoidal height measured with GNSS (ICPs and profile) and extracted from DSMs at these coordinates (Figure 3). These data were also compared against LiDAR data, originating from a topographic survey performed from 16 June 2010 to 13 October 2010 by the French Geographical Institute (IGN) using an airborne laser. The digital terrain model is in the form of a regular grid with a cell size of $1 \mathrm{~m} \times 1 \mathrm{~m}$, derived from LiDAR points.

To assess the horizontal accuracy, the distance between the location of ICPs determined with GNSS and the position given by orthomosaics (white markings on the ground) was measured. This assessment was made possible thanks to the high spatial resolution of orthomosaics $(4.6 \mathrm{~cm} / \mathrm{pix})$.

\subsection{Spatial Analysis}

The DSMs and the orthomosaics were analyzed within a geographical information system (GIS) based on the ArcGIS ${ }^{\circledR}$ software 10.2 (Esri Company, Redlands, CA, USA). The results were exported in a Lambert 93 projection. First, the difference between the DSMs of the first two campaigns was computed and the areas of erosion and accretion were quantified. In order to perform a consistent comparison between both DSMs, a mask was produced to keep only surfaces that were emerged for both campaigns. Changes in the volume of the sandspit located to the south of the study area were also quantified. Finally, a profile was extracted at the end of the sandspit to illustrate the potential of the UAV solutions to quantify detailed morphological changes. This spatial analysis was first performed on a large scale (400 ha), in order to identify the main morphological changes. A finer-scale analysis was also performed over a smaller area ( $33 \mathrm{ha}$ ) to highlight small 3D morphological features that are hardly identifiable from satellite images or other data.

\section{Results}

The first two campaigns were composed of three flights per campaign, which were processed all at once (Figure 5). The last campaign was composed of one flight. The following section presents the DSM and orthomosaic results and their accuracy, evaluated against the GNSS profile and ICPs. 


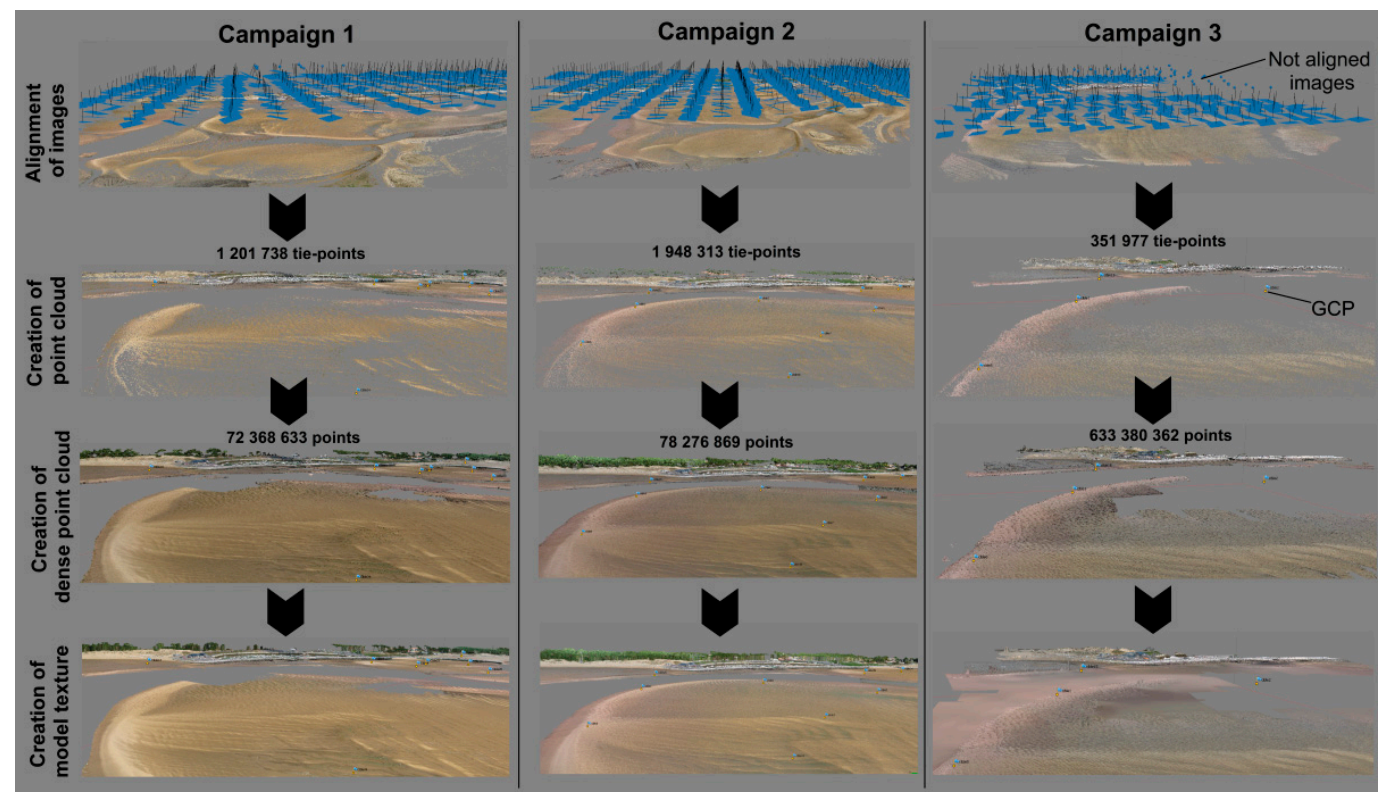

Figure 5. Illustration of the different stages of the photogrammetric process at the flood delta sand bank: alignment of images, creation of point cloud, creation of dense point cloud, creation of model texture.

\subsection{Image Processing}

For each flight, images were georeferenced using the Post-flight Manager tool of the eMotion software. All bright surfaces and water surfaces were masked to avoid error during the photogrammetry process. Image alignment was performed with "high" accuracy and "reference" pair preselection options of Photoscan software (Figure 5). A higher-accuracy setting helps to obtain more accurate image position estimates. In the "reference" preselection mode, the photos overlapping pairs were selected based on the measured image locations. The GCPs were imported, correctly assigned on each image manually and the orientation process was optimized. Optimizing images during the photogrammetric process resulted in small changes of camera parameters (Table 2).

Table 2. Optimization of the camera parameters (pixel).

\begin{tabular}{ccccc}
\hline $\begin{array}{c}\text { Camera } \\
\text { Parameters }\end{array}$ & Initial & $\begin{array}{c}\text { Adjusted } \\
\text { (Campaign 1) }\end{array}$ & $\begin{array}{c}\text { Adjusted } \\
\text { (Campaign 2) }\end{array}$ & $\begin{array}{c}\text { Adjusted } \\
\text { (Campaign 3) }\end{array}$ \\
\hline fx & 3212.47 & 3272.45 & 3274.76 & 3267.49 \\
fy & 3212.47 & 3273.17 & 3275.59 & 3268.28 \\
cx & 2304 & 2334 & 2334.12 & 2333.6 \\
cy & 1728 & 1805.71 & 1808.93 & 1811.37 \\
skew & 0 & 1.44195 & 1.36224 & 1.19702 \\
k1 & 0 & -0.0418731 & -0.0422142 & -0.0409088 \\
k2 & 0 & 0.0426406 & 0.0424654 & 0.0421629 \\
k3 & 0 & -0.0220919 & -0.0217889 & -0.0223425 \\
k4 & 0 & 0 & 0 & 0 \\
p1 & 0 & 0.00422248 & 0.00434259 & 0.00435362 \\
p2 & 0 & 0.00256945 & 0.00258894 & 0.00246941 \\
\hline
\end{tabular}

The resulting residual error computed on GCPs is very close between the three campaigns and around 0.3 pixel on average, with one outlier at 0.97 pixel for the first campaign (Table 3). However, the error distribution ranges from 0.1 and 1 for campaign 1 with a modal class at 0.3 pixel; for the second campaign, the error distribution is narrower and centered on the value of 0.4 pixel. For the third campaign, the modal class is 0.2 pixel (Figure 6). The adverse weather conditions in June for the first campaign may explain the outlier of campaign 1. 

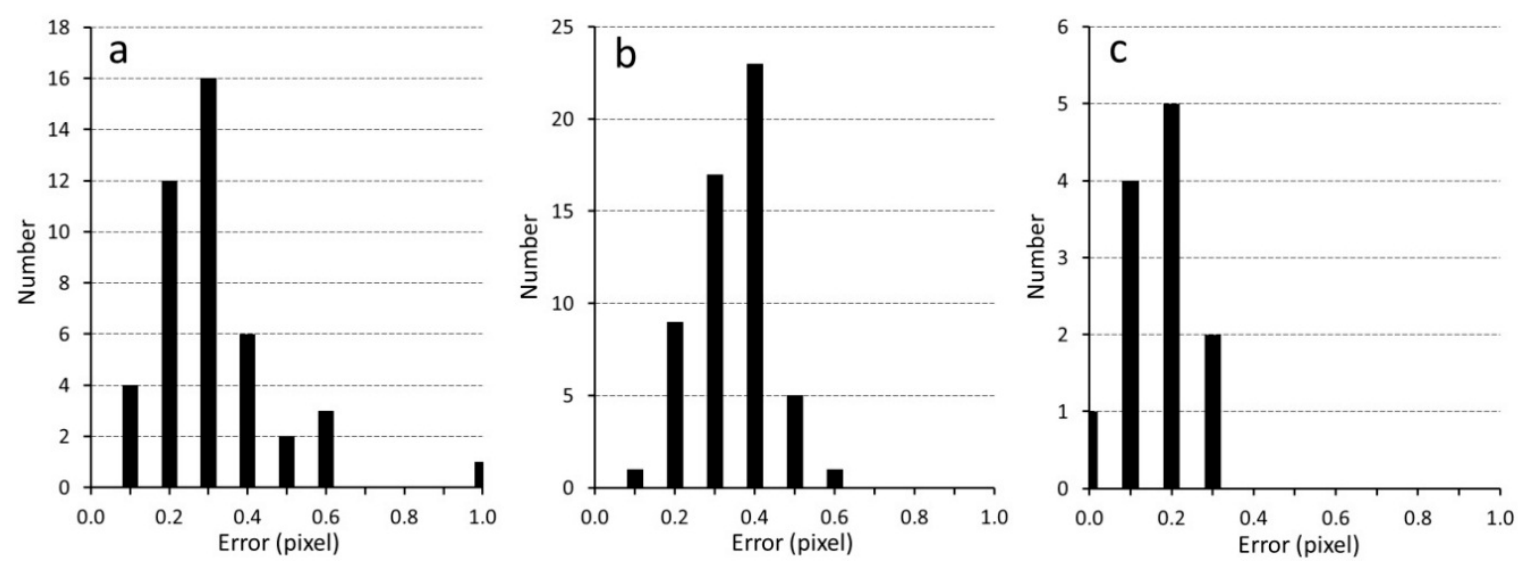

Figure 6. Histograms of errors of images georeferencing from GCPs for (a) campaign 1; (b) campaign 2; and (c) campaign 3.

Table 3. Assessment of the image georeferencing error from GCPs for the three campaigns.

\begin{tabular}{lccccccc}
\hline Campaigns & $\begin{array}{c}\text { No. Photo } \\
\text { Used }\end{array}$ & $\begin{array}{c}\text { No. Tie } \\
\text { Points }\end{array}$ & $\begin{array}{c}\text { X Error } \\
(\mathbf{m})\end{array}$ & $\begin{array}{c}\text { Y Error } \\
(\mathbf{m})\end{array}$ & $\begin{array}{c}\text { Z Error } \\
(\mathbf{m})\end{array}$ & Error (m) & Error (pixel) \\
\hline Campaign 1 & 672 & 1201738 & 0.041 & 0.077 & 0.018 & 0.089 & 0.304 \\
Campaign 2 & 643 & 1948313 & 0.012 & 0.009 & 0.012 & 0.019 & 0.316 \\
Campaign 3 & 301 & 351977 & 0.004 & 0.084 & 0.016 & 0.092 & 0.292 \\
\hline
\end{tabular}

Before investigating the accuracy of the DSM produced by Photoscan, it is essential to visualize the nadir and overlap of the images for the three campaigns (Figure 7). As previously noted, flight plans had a lateral overlap of $60 \%$ and a longitudinal overlap of $75 \%$. According to the overlapping maps, the image number decreases from nine in the study area center to two along the periphery. During the third campaign, the recovery did not exceed eight images.
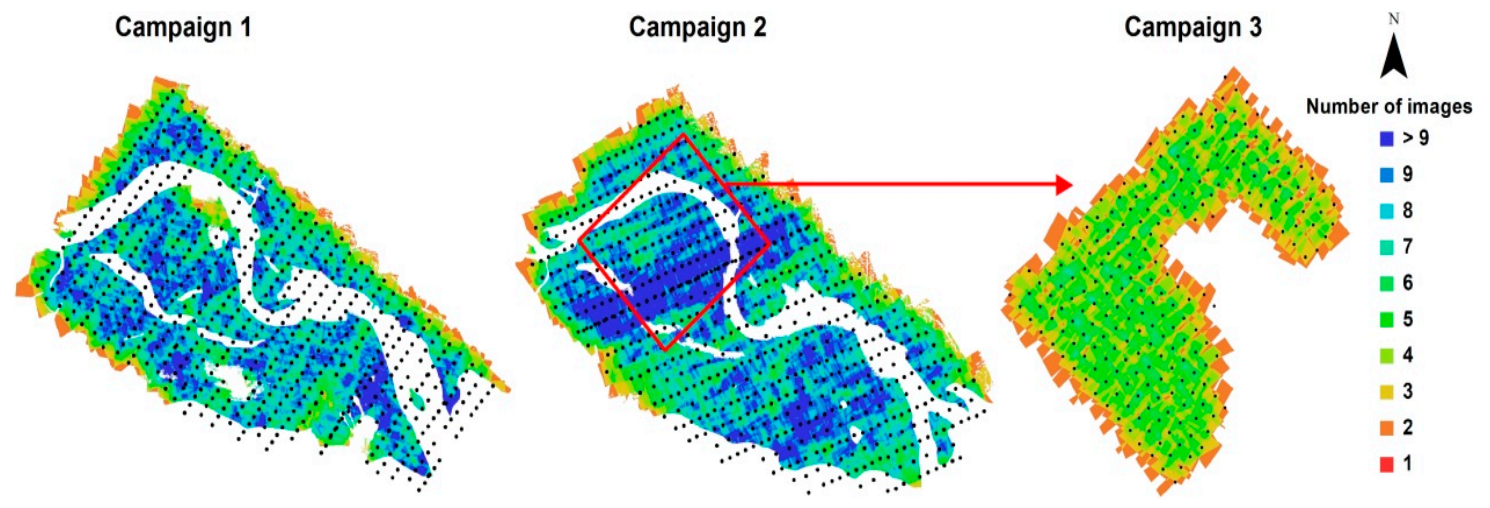

Figure 7. Image recovery maps for the three campaigns. Black points correspond to nadir images.

\subsection{Digital Surface Model}

\subsubsection{Construction of the Digital Surface Model}

The dense point cloud was performed using the "medium quality" and an "aggressive" depth filtering options of Photoscan. These settings help to reduce processing time when dealing with a large number of tie points, as is the case here. Then, the mesh of the ground height was computed from the dense cloud without interpolation of the data (Figure 5), which avoids filling in areas where data are lacking. On the sand, and particularly on white and smooth sand areas, the generation of the DSM was difficult because the model did not find a sufficient number of tie points. 
Figure 8 shows the DSMs obtained for each campaign. Except in areas where not enough tie points were found or water coverage differed between campaigns 1 and 2, the overlap between the two full DSMs is good. Outside the anthropized area, the ground is relatively flat and smooth and its height ranges from 45 and $47 \mathrm{~m}$, except at the end of the sandspit where some dunes reach $49 \mathrm{~m}$. In order to demonstrate the relevance of this high spatial density of data, a DSM was generated on the central sand bank with a grid size of $2 \mathrm{~cm}$ and several levels of zoom are shown in Figure 8c. The first two levels of zoom in the left panels show the development of tidal dunes with a wavelength of the order of $10 \mathrm{~m}$ and a height of $0.3 \mathrm{~m}$. The third zoom level in the right panel shows the development of superimposed bedforms with a wavelength of the order of $1 \mathrm{~m}$ and a height of $0.10 \mathrm{~m}$.

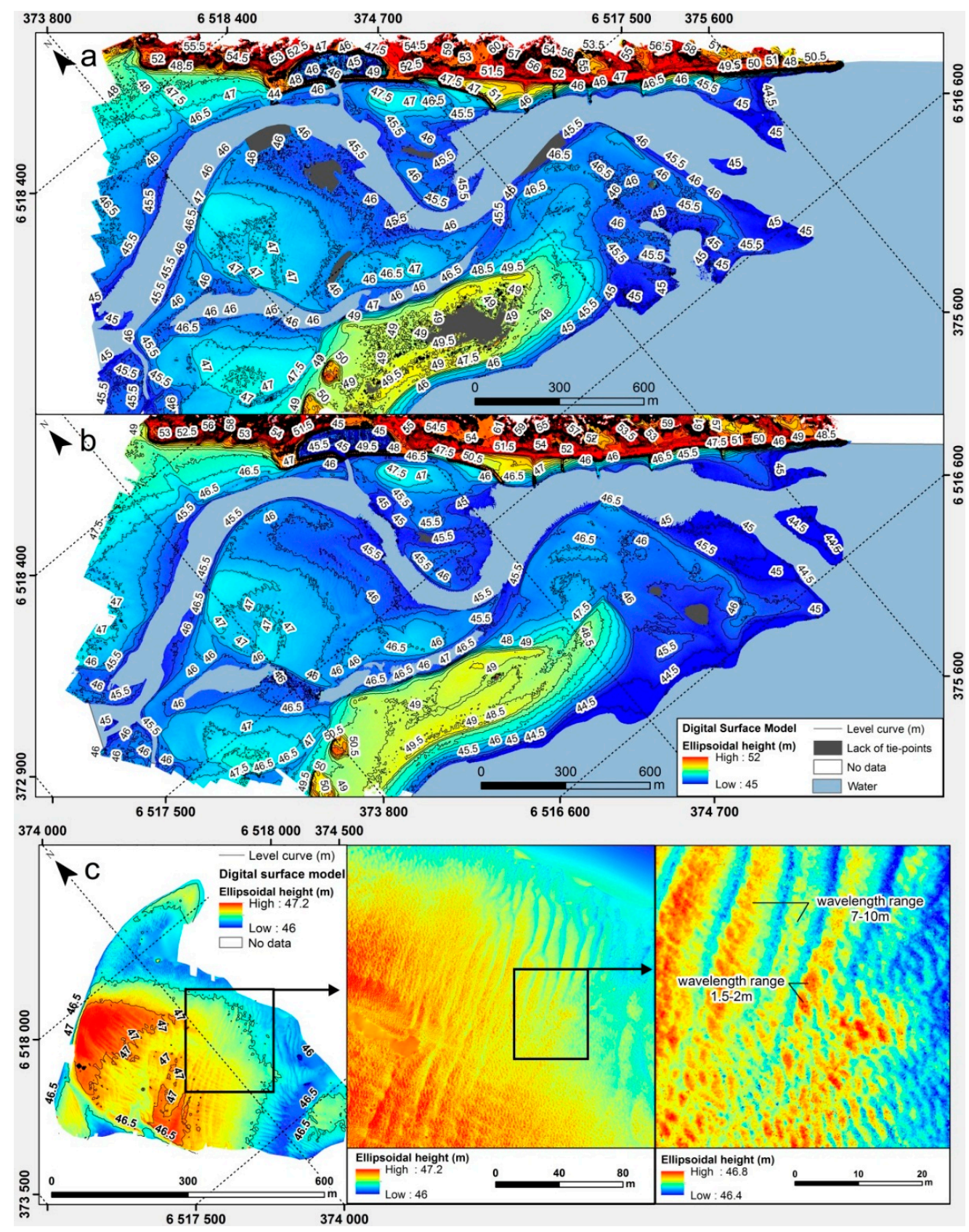

Figure 8. DSMs obtained from the three campaigns: (a) campaign 1; (b) campaign 2; and (c) campaign 3. The spatial resolutions are $20 \mathrm{~cm}$ for (a) and (b) and $2 \mathrm{~cm}$ for (c). Isolines computed over 5-m-resolution DSMs were superimposed every $0.5 \mathrm{~m}$ to improve the representation of the morphology on figures a-c. Grey areas correspond to lack of tie points. White areas correspond to no data (inside the sand banks). 


\subsubsection{Vertical Accuracy of Digital Surface Models}

- With the GNSS profile

To assess the vertical accuracy of the DSMs, the ellipsoidal heights of the GNSS profile surveyed during campaign 2 (Figure 4) were compared against the heights of the points extracted from the DSM at the same coordinates (Figure 9a). The DSM heights are close to that of the GNSS profile, although with a slight positive bias of the order of $10 \mathrm{~cm}$. Some larger differences appear at the beginning of the profile (first 100 meters) and correspond to the trough of bedforms where water was still present and caused disturbance in the photogrammetry process. The histogram of the height difference between the DSM and the GNSS profile shows that the main part of the vertical errors ranges from 5 to $15 \mathrm{~cm}$ (Figure 9b). The arithmetic average discrepancy is $6.78 \mathrm{~cm}$ and the root mean square discrepancy is $9.44 \mathrm{~cm}$. The precision of the GNSS surveys and the precision of the DSM were added to produce a conservative cumulative error of $\pm 20 \mathrm{~cm}$. Since the GNSS profile has only been surveyed during campaign 2 , this cumulative error is only valid for this campaign.

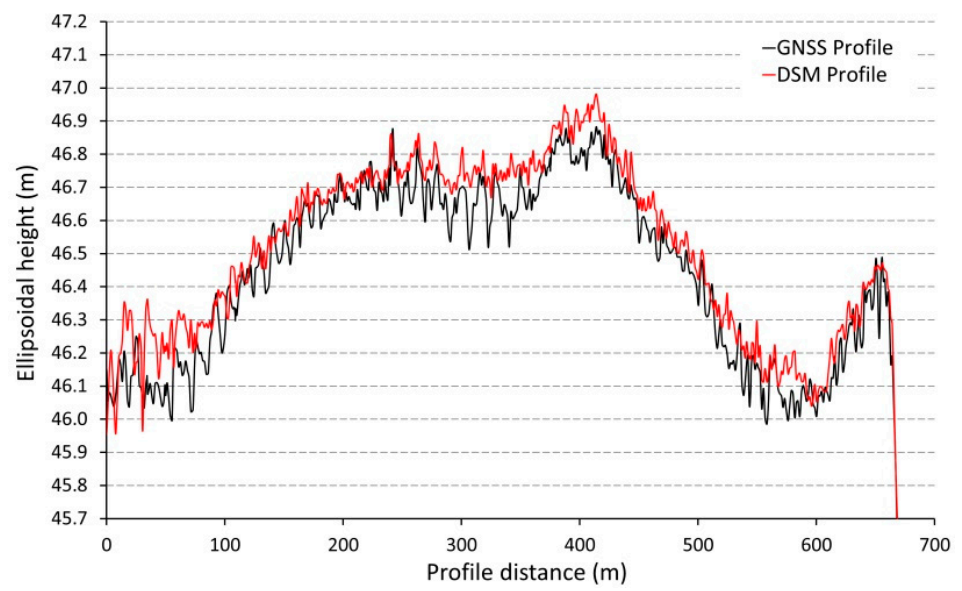

(a)

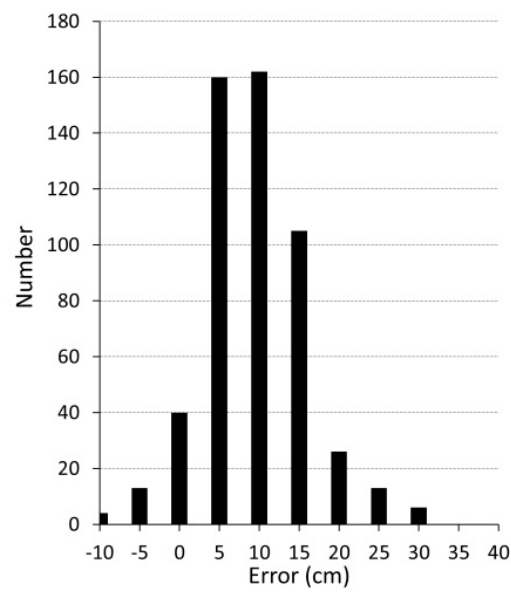

(b)

Figure 9. (a) Ellipsoidal heights of the GNSS profile (in black) and extracted from the DSM (in red) of campaign 2 and (b) histogram of the ellipsoidal height differences.

- With independent control points

To determine the vertical accuracy of DSMs for the entire study, error calculations were made on the ICPs. ICPs were surveyed within the whole anthropized area located to the north of the study area. Those ICPs consist of ground markings that can be considered as invariant between campaigns (Figure 4).

The scatter plot of the ICPs' ellipsoidal height between DSM data and GNSS data (Figure 10) shows firstly that the scatter is small and comparable for the three datasets considered (campaigns 1,2 and LiDAR). The root mean square discrepancy (RMSD) is $17 \mathrm{~cm}$ for campaign 1 and $16 \mathrm{~cm}$ for campaign 2, with a slight negative bias of $-0.08 \mathrm{~m}$ and $-0.07 \mathrm{~m}$, respectively. The LiDAR data are slightly less accurate, with a RMSD of $0.21 \mathrm{~m}$ and a slight positive bias of $0.08 \mathrm{~m}$. Here, we referred to discrepancy rather than error because GNSS data have their own errors. Since the same GNSS were used to position GCPs used in the photogrammetry process, the errors associated with DSM and GNSS data are not strictly independent, and therefore the computation of total error is not a trivial task. Alternatively, we adopted a conservative approach where we linearly summed the error estimation of the GNSS data and the RMSD of the DMS data described above. This process resulted in a cumulative error of $\pm 27 \mathrm{~cm}$. Because ICPs were surveyed on stable areas in time, and therefore used in all DSMs, this cumulative error is used to define a vertical accuracy of UAV-derived DSMs. 


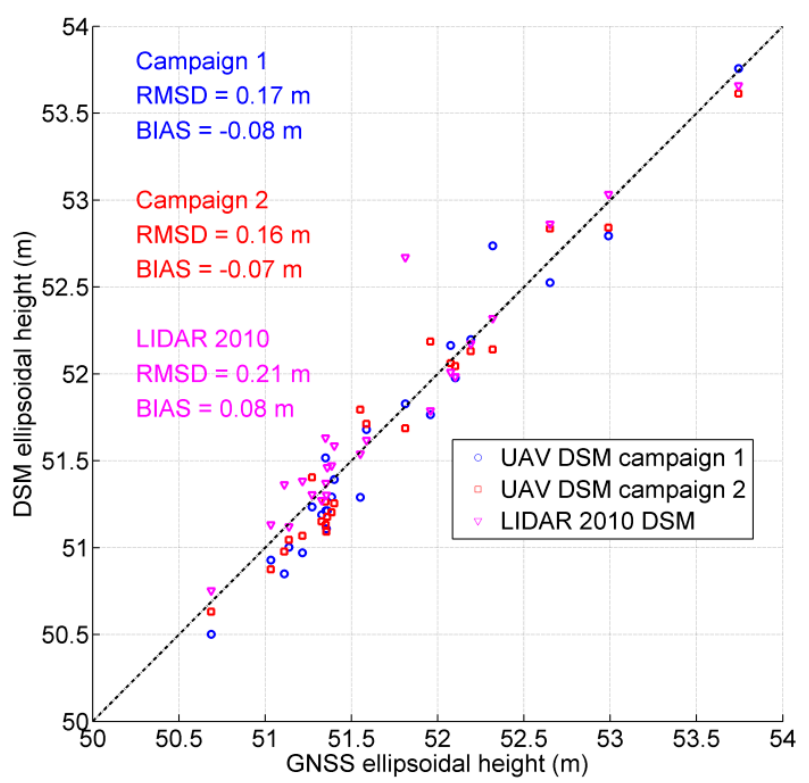

Figure 10. Scatter plot of ICPs' ellipsoidal heights between DSMs data and GNSS data. The blue dots correspond to campaign 1 while the red dots correspond to campaign 2.

\subsection{Horizontal Accuracy of Orthomosaics}

For campaign 1, planimetric errors are distributed between 3.55 and $34.14 \mathrm{~cm}$, with a root mean square discrepancy of $12.84 \mathrm{~cm}$ (Figure 11). The values obtained for campaign 2 are similar and range from 2.78 to $25.29 \mathrm{~cm}$, with a root mean square discrepancy of $12.36 \mathrm{~cm}$.

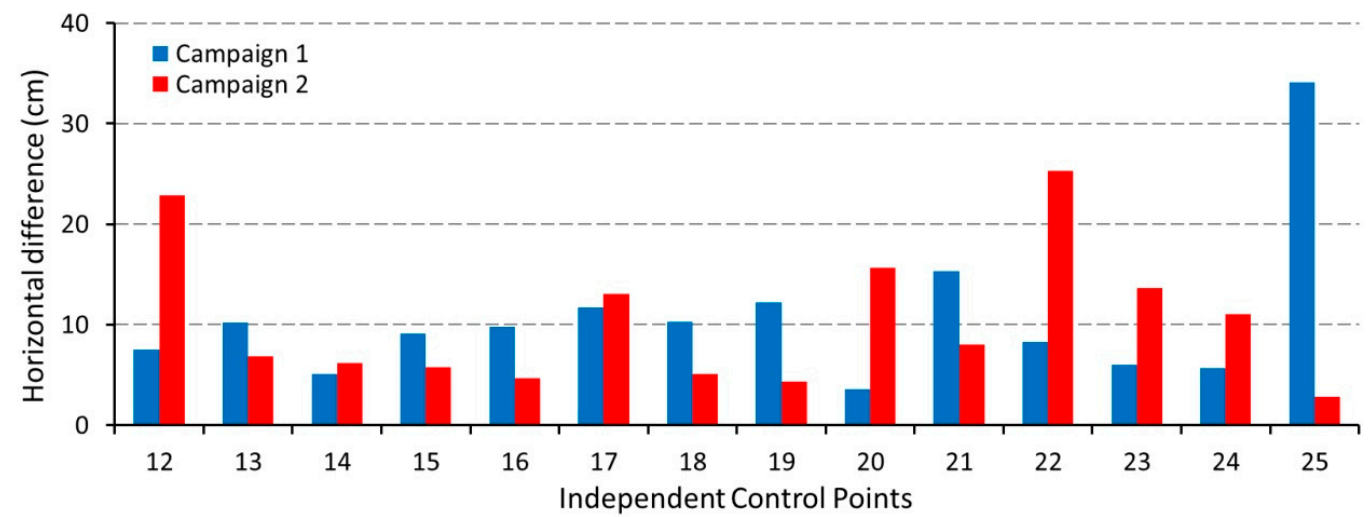

Figure 11. Horizontal differences between GNSS ICPs and orthomosaics from campaigns 1 and 2.

The horizontal error given for the GNSS receiver $(1 \mathrm{~cm})$ and the operator error when measuring the difference between ICPs and orthomosaics (2 pixels which is $9.2 \mathrm{~cm}$ ) must be added to the first error, which results in a xy cumulative error of $\pm 23 \mathrm{~cm}$. Because ICPs were surveyed on stable areas used in all orthomosaics, this cumulative error was used to define a horizontal accuracy of the orthomosaics.

\subsection{Morphological Changes}

At the scale of the whole tidal inlet, the comparative study of these DSMs shows that significant changes are restricted to a few areas only, while the main part of the system remained stable within the accuracy of our method (Figure 12). Among the areas where significant changes occurred, the terminal portion of the sandspit of Bonne-Anse Bay progressed by about $100 \mathrm{~m}$ while it significantly eroded updrift. Around the inlet main channel, a new channel appeared, cutting the ebb delta sand bank. Also, the main channel globally enlarged over the studied period. 


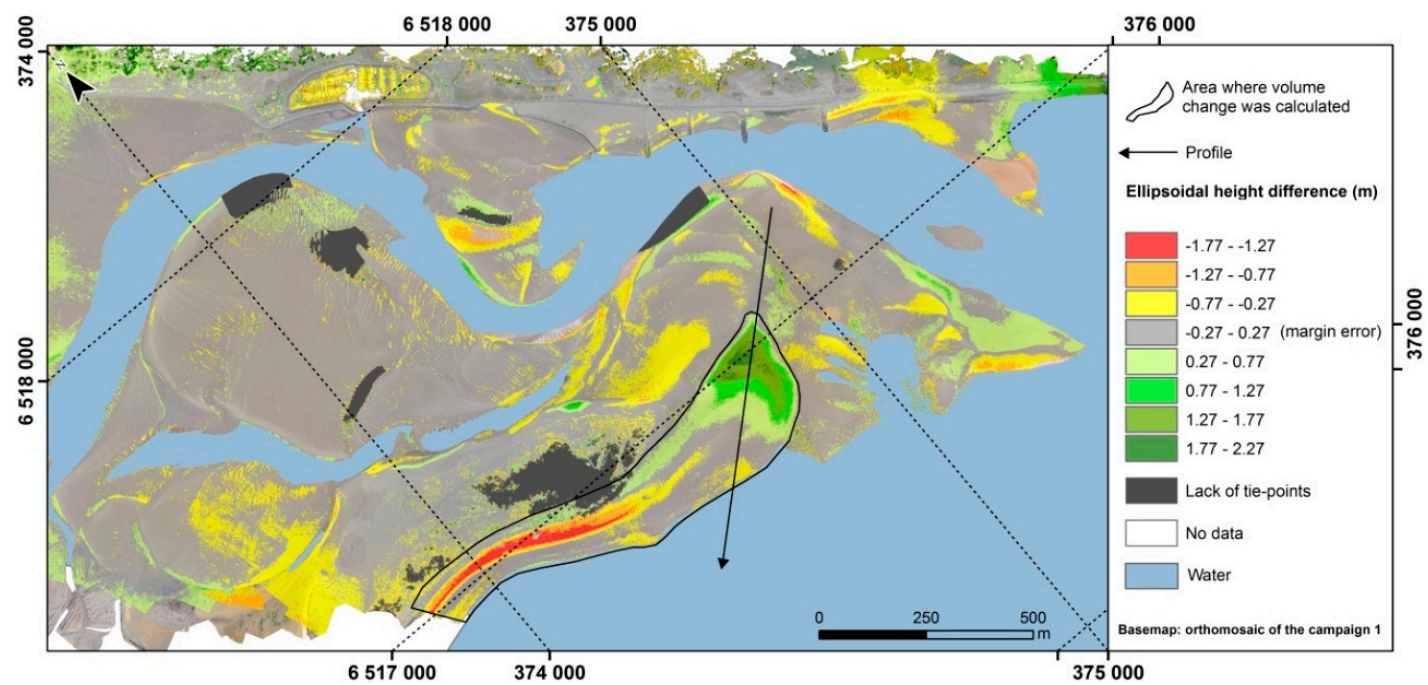

Figure 12. Ellipsoidal height difference during the studied period (from campaign 1 to campaign 2). The results are presented on the orthomosaic of the campaign 2. The shade of red corresponds to areas where erosion occurred and the shade of green corresponds to areas where accretion occurred. Light grey means that the changes are not significant according to the margin of error computed previously. Dark grey areas correspond to lack of tie points and white areas to no data. The arrow corresponds to the location of the topographic profile plotted on Figure 13.

Over the main part of the study area, changes are included within the error interval $( \pm 0.27 \mathrm{~m})$ (Figure 12), which shows that the mouth of the bay remained globally stable between June and October 2015. The largest morphological changes took place at the sandspit, with vertical differences ranging from -1.77 to $+2.27 \mathrm{~m}$.

A first result of this analysis is the loss of sediment upstream and the gain of sediment downstream. The sedimentary budget of the sandspit area is positive, with a gain of about $13,000 \mathrm{~m}^{3}$. Erosive areas (yellow, orange and red in Figure 12) lost about $37,300 \mathrm{~m}^{3}$, while areas in accretion (shades of green) earned about $50,300 \mathrm{~m}^{3}$. The cross-shore profile of Figure 13 illustrates that this sediment accretion reached about $1.6 \mathrm{~m}$ vertically over a distance of $115 \mathrm{~m}$.

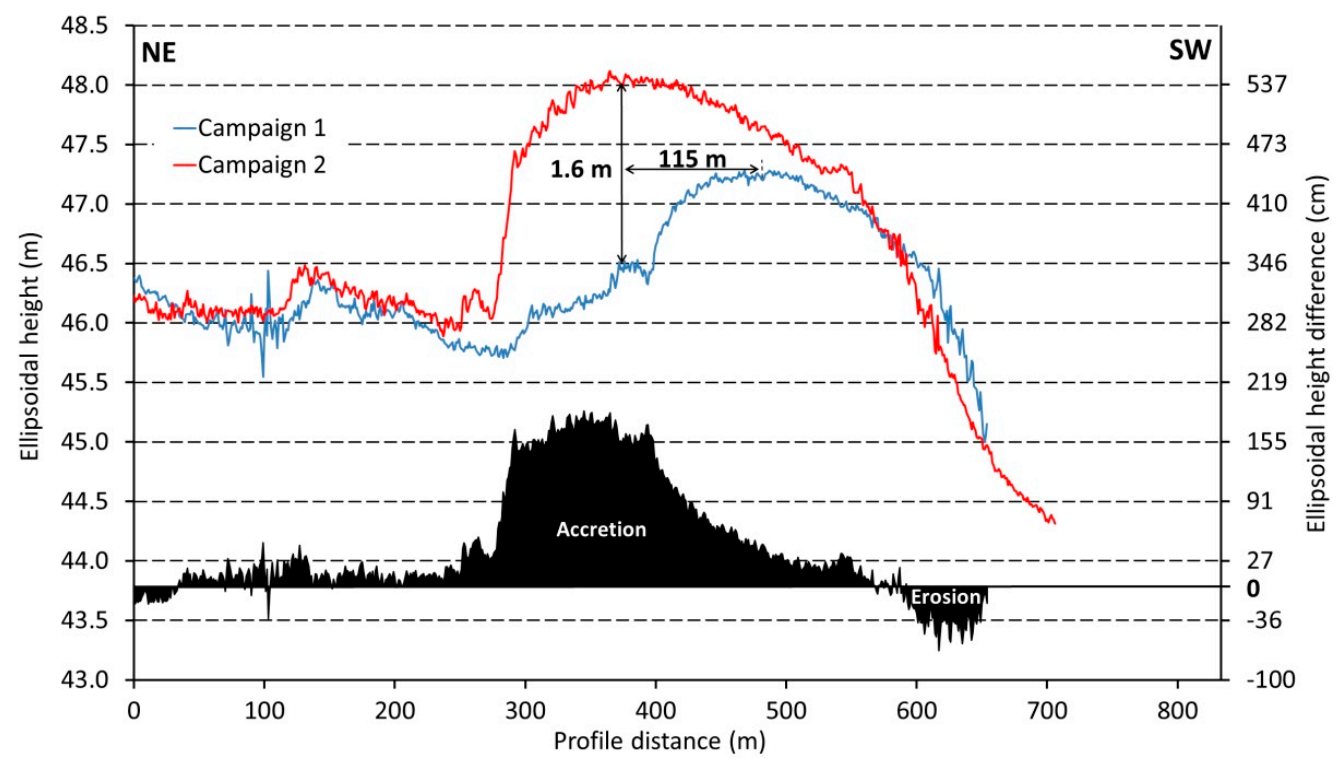

Figure 13. Ellipsoidal height profiles, extracted from the DSM of campaigns 1 (blue) and 2 (red) and difference between both (black). 


\section{Discussion}

The morphological changes of a lagoon-inlet system were monitored over a three-month period for the first time by means of UAV-based photogrammetry. Compared to similar studies realized in a coastal environment $[17,19]$, our UAV solution was deployed over a larger surface area (400 ha vs. a few tens of ha) and repetitively, which allowed characterizing topographic changes with a high resolution and quantifying erosion/accretion patterns. This section discusses the relevance of our method compared to classical LiDAR and GNSS methods and also provides an example of interpretation of the observed morphological changes.

\subsection{Relevance of the UAV Method Compared to GNSS and LiDAR}

The vertical accuracy of the method presented in this study was shown to be of the order of $17 \mathrm{~cm}$, which is comparable to LiDAR or TLS surveys but slightly less accurate than GNSS-based surveys [19,31]. Compared to LiDAR surveys, the method proposed here is several orders of magnitude cheaper, while providing two orders of magnitude finer spatial resolution [11-13]. Compared to GNSS surveys, the new method is much faster while providing much denser spatial information, although with a slightly lesser accuracy [31]. This vertical accuracy was calculated from ICPs located in the limit of the area covered by the UAV flight where the number of images decline to values between two and four (Figure 7): it is thus expected that our error estimate is conservative. Furthermore, the strong crosswind during the campaign in June generated oblique images unusable during the photogrammetric process. In the next field missions, it will be important to extend the flight plan in order to have a better recovery of peripheral areas. The comparison between DSMs of the two main campaigns and LiDAR from 2010 confirms the quality of the DSMs derived from the UAV images (Figure 10).

Lagoon-inlet systems correspond to particular environments where access is difficult due to the presence of many channels. The solution used in this study allows computing a DSM at very high resolution while being non-intrusive. In addition, classical LiDAR and GNSS topographic surveys, which usually allow computing DSMs with a spatial resolution in the range of 1-10 m, would offer a very rough representation of the largest tidal dunes imaged with our UAV solution (Figure 8) while the smallest bedforms would not be represented at all. This decisive improvement would, for instance, allow investigating residual sediment transport, which is indicated by the slip face of the dunes. Another perspective would be to improve the parameterization of bottom friction in hydrodynamic numerical models based on the dimension of these bedforms.

\subsection{Interpretation of the Morphological Changes at the Sandspit}

As shown in the previous section, the main morphological change during the surveyed period concerns the development of the sandspit by more than $100 \mathrm{~m}$. Even if GCPs are absent close to the erosion area (to the south of the sandspit, shade of red color on Figure 12), it can be assumed that the accuracy of the DSM in this area is similar to that computed previously. Indeed, the image recovery on this area is up to six images for both campaigns, suggesting that the photogrammetry process was accurate. This sediment accretion roughly balances the erosion that occurred updrift, although the sediment balance remains positive over this three-month period. While the development of sandspits is well documented and explained by the presence of longshore currents driven by the breaking of oblique waves, the amount of sand moved for a summer period remains exceptional for the study area. Indeed, Chaumillon et al. [7] showed that, during the summer period, offshore swells tend to be smaller, of shorter period and originate from the northerly direction so that the study area was exposed to residual waves with significant height in the range of $0.1-0.5 \mathrm{~m}$. Such small waves would not be energetic enough to move volumes of sand of the order of $50,000 \mathrm{~m}^{3}$. In order to better understand this surprising behavior, we analyzed a time series of wave height measured offshore of the study area (Figure $1,1.83^{\circ} \mathrm{W} ; 45.91^{\circ} \mathrm{N}$, water depth $=50 \mathrm{~m}$ ) over 2014-2015. Figure 14a reveals the occurrence 
of several events inducing wave heights larger than $5 \mathrm{~m}$ in August and September, which is rather uncommon for the study area and corresponds to winter conditions [16]. To evaluate the local effect of these uncommon storm waves in summer, we extended the wave hindcast presented in Chaumillon $e t$ al. [7] up to December 2015. This computation revealed firstly the occurrence of two events in August and September, characterized by waves of significant height exceeding $1.5 \mathrm{~m}$ in front of the inlet, which usually occurs in winter. We also forced the simple Coastal Engineering Research Center (CERC) [32] longshore transport formula with wave parameters at breaking extracted from this hindcast and followed the methodology described in Bertin [33] (Figure 14b). The cumulated longshore transport was estimated to be $31,000 \mathrm{~m}^{3}$ over the studied period, which is about three times larger compared to classical summers. Indeed, the cumulated longshore transport over the studied period represents about $20 \%$ of the yearly value, while the summer contribution of the yearly longshore transport is usually less than $10 \%$ considering the 36-year hindcast of Bertin [33]. However, morphological changes are controlled by the divergence of sand fluxes and not the potential longshore transport as computed here. In the present case, our computation can only explain that the sediment accretion that occurred at the tip of the sandspit results from a combination of the longshore transport that takes place along the whole spit and the erosion area that developed immediately updrift. The physical processes responsible for these morphological changes will have to be analyzed in detail using the process-based modeling system under development in our lab [34]. The detailed morphological changes evidenced from our UAV image mapping will be of great help to validate our modeling system.

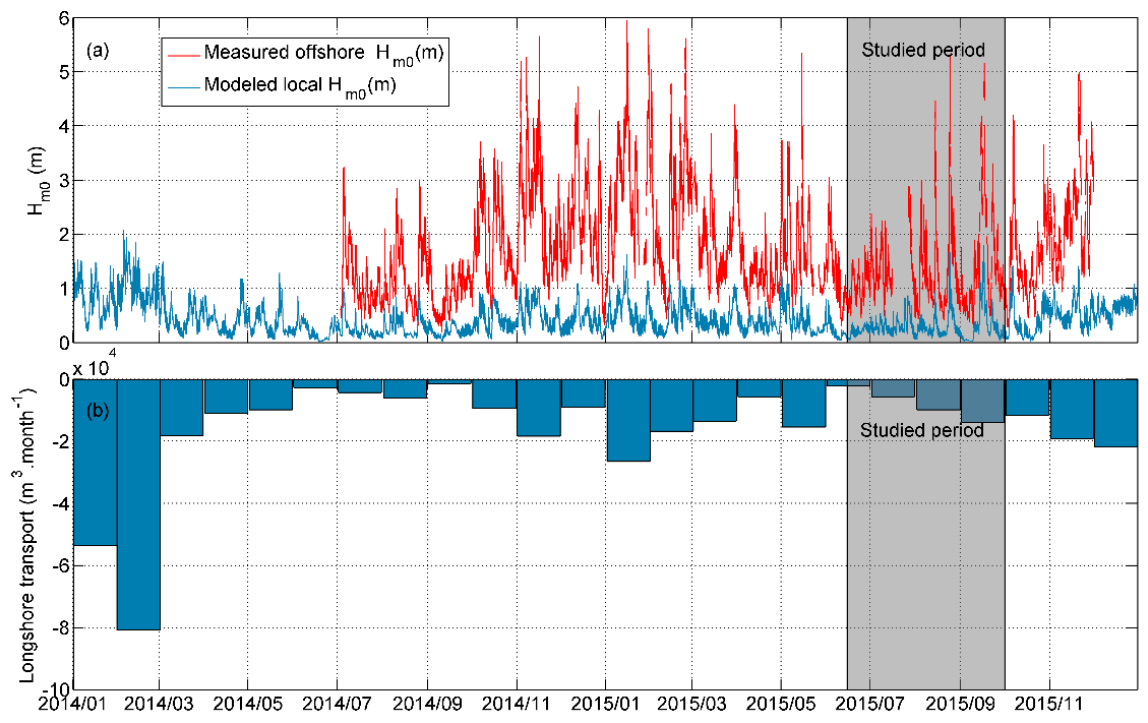

Figure 14. (a) Significant wave height measured offshore of Oléron Island (red) and simulated in front of the inlet (blue) between July 2014 and December 2015; (b) Longshore transport estimated with wave parameters at breaking extracted from the wave hindcast.

\section{Conclusions}

This study demonstrated the potential of UAV methods using a photogrammetry approach (SFM algorithm) to monitor tidal inlet environments. This solution allows surveying inter- and supra-tidal topography with a non-intrusive method, over a large geographic area (400 ha) with very dense spatial information $(4.6 \mathrm{~cm}$ horizontal resolution). From three campaigns spanning a three-month period, DSMs and orthomosaics were produced. GCPs were used to georeference the DSMs and the comparison with GNSS data (profile and ICPs) demonstrated the good accuracy of our method, with a root mean square discrepancy lower than $17 \mathrm{~cm}$, which is slightly better than that of the LiDAR data acquired in this area in 2010. Based on this accuracy, a differential map was computed, which revealed that the main part of the study area remained stable, although the inlet channel tended to enlarge and the sandspit prograded by more than $100 \mathrm{~m}$. The very detailed morphological changes revealed by our 
method will be very useful to further analyze the causes for this sandspit accretion. In addition, our method allows for the mapping of tidal dunes up to a wavelength of the order of $1 \mathrm{~m}$ and a height of $0.1 \mathrm{~m}$, which opens new perspectives to understanding residual sand fluxes on sand banks and also to better parameterize bottom friction in process-based models.

The methodology developed here was shown to be suitable for such a coastal area subjected to a strong tidal influence, which promotes the development of bedforms almost everywhere. These bedforms provides a large density of visual landmarks on most images, which optimizes the generation of tie points in the SFM algorithm. The efficiency of this methodology will therefore have to be verified for wave-dominated beaches or eolian dunes where lower contrast and fewer landmarks may be found. A possible improvement would be to pre-process images in order to increase their contrast and therefore enhance the photogrammetric process. Also, an algorithm will be developed to identify and automatically mask water areas, a process that was done manually in this study.

Acknowledgments: This study was conducted in the scope of the project DYNAMO, funded by the French Agency for Research (Grant agreement $\mathrm{n}^{\circ}$ ANR-12-JS02-00008-01) and the project EVEX, funded by Region Poitou-Charentes in the framework of the Regional Chair program. Antoine Dumon and Nicolas Lachaussée are acknowledged for their help on the field and Médéric Gravelle provided valuable advices to process GNSS data.

Author Contributions: All authors contributed in a substantial way to the manuscript. N.L. and X.B. proposed and conceived the experiments; N.L., B.G., F.P. and X.B. performed the field work; B.M. analyzed the data; All authors contributed to the drafting of the paper; N.L. supervised the study at all stages.

Conflicts of Interest: The authors declare no conflict of interest.

\section{References}

1. Thieler, E.R.; Danforth, W.W. Historical Shoreline Mapping (I): Improving Techniques and Reducing Positioning Errors. J. Coast. Res. 1994, 10, 549-563. Available online: http:/ /www.jstor.org/stable/4298252 (accessed on 15 December 2015).

2. Quartel, S.; Addink, E.A.; Ruessink, B.G. Object-oriented extraction of beach morphology from video images. Int. J. Appl. Earth Obs. Geoinf. 2006, 8, 256-269. [CrossRef]

3. Pardo-Pascual, J.E.; Almonacid-Caballer, J.; Ruiz, L.A.; Palomar-Vazquez, J. Automatic extraction of shorelines from Landsat TM and ETM+ multi-temporal images with subpixel precision. Remote Sens. Environ. 2012, 123, 1-11. [CrossRef]

4. Ford, M. Shoreline changes interpreted from multi-temporal aerial photographs and high resolution satellite images: Wotje Atoll, Marshall Islands. Remote Sens. Environ. 2013, 135, 130-140. [CrossRef]

5. Ryu, J.H.; Won, J.S.; Min, K.D. Waterline extraction from Landsat TM data in a tidal flat: A case study in Gomso Bay, Korea. Remote Sens. Environ. 2002, 83, 442-456. [CrossRef]

6. Maiti, S.; Bhattacharya, A.K. Shoreline change analysis and its application to prediction: A remote statistics based approach. Mar. Geol. 2009, 247, 11-23. [CrossRef]

7. Chaumillon, E.; Ozenne, F.; Bertin, X.; Long, N.; Ganthy, F. Wave climate and inlet channel meander bend control spit breaching and migration of a new inlet: La Coubre Sandspit, France. J. Coast. Res. 2014, 70, 109-114. [CrossRef]

8. Long, N.; Pouget, F.; Bellec, A.; Chaumillon, E.; Bertin, X. Automatic extraction of shorelines from multi-temporal and very high resolution images to monitor coastal ecosystem. In Proceedings of the 5th Geographic Object-based Image Analysis Conference, Thessaloniki, Greece, 21-24 May 2014; Volume 3, pp. 245-250.

9. Perko, R.; Raggam, H.; Gutjahr, K.; Schardt, M. Assessment of the mapping potential of Pleiades stereo and triplet data. In Proceedings of the ISPRS conference on ISPRS Annals of the Photogrammetry, Remote Sensing and Spatial Information Sciences, Zurich, Switzerland, 5-7 September 2014; Volume II-3, pp. 103-109.

10. Poli, D.; Remondino, F.; Angiuli, E.; Agugiaro, G. Evaluation of Pleiades-1A triplet on Trento testfield. In International Archives of the Photogrammetry, Remote Sensing and Spatial Information Sciences, Proceedings of the ISPRS Hannover Workshop, Hannover, Germany, 21-24 May 2012; Volume XL-1, pp. 287-292. 
11. White, S.A.; Wang, Y. Utilizing DEMs derived from LIDAR data to analyze morphologic change in the North Carolina coastline. Remote Sens. Environ. 2003, 85, 39-47. [CrossRef]

12. Nagihara, S.; Kevin, R.; Mulligan, R.; Xiong, W. Use of the tree-dimensional laser scanner to digitally capture the topography of sand dunes in high spatial resolution. Earth Surf. Process. Landf. 2004, 29, 391-398. [CrossRef]

13. Letortu, P.; Costa, S.; Maquaire, O.; Delacourt, C.; Augereau, E.; Davidson, R.; Suanez, S.; Nabucet, J. Retreat rates, modalities and agents responsible for erosion along the coastal cliffs of Upper Normandy: The contribution of terrestrial laser scanning. Geomorphology 2015, 245, 3-14. [CrossRef]

14. Castelle, B.; Marieu, V.; Bujan, S.; Splinter, K.D.; Robinet, A.; Sénéchal, N.; Ferreira, S. Impact of the winter 2013-2014 series of severe western Europe storms on a double barred sandy coast: Beach and dune erosion and megacusp embayments. Geomorphology 2015, 238, 135-148. [CrossRef]

15. Taveira-Pinto, F.; Silva, R.; Barbosa, J. Coastal Erosion Along the Portuguese Northwest Coast Due to Changing Sediment Discharges from Rivers and Climate Change. In Global Change and Baltic Coastal Zones; Schernewski, G., Hofstede, J., Neumann, T., Eds.; Global Change and Baltic Coastal Zones, Coastal Research Library-Series; Springer: Dordrecht, The Netherlands, 2011; Volume 1, pp. 135-151.

16. Bertin, X.; Castelle, B.; Chaumillon, E.; Butel, R.; Quique, R. Estimation and inter-annual variability of the longshore transport at a high-energy dissipative beach: The St Trojan beach, SW Oléron Island, France. Cont. Shelf Res. 2008, 28, 1316-1332. [CrossRef]

17. Gonçalves, J.A.; Henriques, R. UAV photogrammetry for topographic monitoring of coastal areas. ISPRS J. Photogramm. Remote Sens. 2015, 104, 101-111. [CrossRef]

18. Casella, E.; Rovere, A.; Pedroncini, A.; Mucerino, L.; Casella, M.; Cusati, L.A.; Vacchi, M.; Ferrari, M.; Firpo, M. Study of wave runup using numerical models and low-altitude aerial photogrammetry: A tool for coastal management. Estuar. Coast. Shelf Sci. 2014, 149, 160-167. [CrossRef]

19. Mancini, F.; Dubbini, M.; Gatelli, M.; stecchi, F.; Fabbri, S.; Gabbianelli, G. Using Unmanned Aerial Vehicles (UAV) for the high-resolution reconstruction of topography: the Structure for Motion approach on coastal environments. Remote Sens. 2013, 5, 6880-6898. [CrossRef]

20. Haala, N. Comeback of Digital Image Matching. In Photogrammetric Week; Wichmann Verlag: Heidelberg, Germany, 2009; pp. 289-301.

21. Colomina, I.; Molina, P. Unmanned aerial systems for photogrammetry and remote sensing: A review. ISPRS J. Photogramm. Remote Sens. 2014, 92, 79-97. [CrossRef]

22. Klemas, V.V. Coastal and environmental remote sensing from unmanned aerial vehicles: On overwiev. J. Coast. Res. 2015, 31, 1260-1267. [CrossRef]

23. Jutzi, B.; Weinmann, M.; Meidow, J. Weighted data fusion for UAV-borne 3D mapping with camera and line laser scanner. Int. J. Image Data Fusion 2014, 5, 226-243. [CrossRef]

24. Stødle, D.; Borch, N.; Solbø, S.; Storvold, R. High performance visualisation of UAV sensor and image data with raster maps and topography in 3D. Int. J. Image Data Fusion 2014, 5, 244-262. [CrossRef]

25. Clapuyt, F.; Vanacker, V.; Van Oost, K. Reproducibility of UAV-based earth topography reconstruction based on Structure-from-Motion algorithms. Geomorphology 2015. in press. [CrossRef]

26. Robertson, D.P.; Cipolla, R. Structure from Motion, in Practical Image Processing and Computer Vision; Varga, M., Ed.; John Wiley \& Sons: Milton, Australia, 2009; Chapter 13; p. 24.

27. Ullman, S. The Interpretation of Structure from Motion; The Royal Society: London, UK, 1979; p. 35. Available online: http:/ / publications.ai.mit.edu/ai-publications/pdf/AIM-476.pdf (accessed on 15 December 2015).

28. Deseilligny, M.P.; Clery, I. Apero, an open source bundle adjustment software for automatic calibration and orientation of set of images. In Proceedings of the ISPRS International Workshop on 3D Virtual Reconstruction and Visualisation of Complex Architectures, Trento, Italy, 2-4 March 2011; pp. 269-276.

29. Agisoft LLC. Agisoft Photoscan User Manual, Professional Edition, Version 0.9.0; Agisoft LLC: St. Petersburg, Russia, 2012.

30. Takasu, T. RTKLIB Version 2.4.2 Manual 2013; p. 183. Available online: http://www.rtklib.com/prog/ manual_2.4.2.pdf (accessed on 10 February 2016).

31. Lee, J.M.; Park, J.-Y.; Choi, J.-Y. Evaluation of su-aerial topographic surveying techniques using total station and RTK-GPS for application in macrotidal sand beach environment. J. Coast. Res. SI 2013, 65, 535-540. [CrossRef] 
32. CERC. Shore Protection Manual, 4th ed.; US Army Engineer Waterways Experiment Station, Coastal Engineering Research Center, US Government Printing Office: Washington, DC, USA, 1984.

33. Bertin, X. Dynamique Hydro-Sédimentaire Des Côtes Dominées par la Houle et par la Marée. Habilitation Thesis to Coordinate Research Activities; La Rochelle University: La Rochelle, France, 2015; p. 135.

34. Guérin, T.; Bertin, X.; Dodet, G. A numerical scheme for coastal morphodynamic modelling on unstructured grids. Ocean Modell. 2016. accepted. [CrossRef]

(C) 2016 by the authors; licensee MDPI, Basel, Switzerland. This article is an open access article distributed under the terms and conditions of the Creative Commons Attribution (CC-BY) license (http://creativecommons.org/licenses/by/4.0/). 